\title{
Study on Electrochemistry and Nucleation Process of Nickel Electrodeposition
}

\author{
Yundan Yu, Lixia Sun ", Hongliang Ge, Guoying Wei, Li Jiang \\ College of Materials Science and Engineering, China Jiliang University, China \\ *E-mail: lixiasun1982@sina.com
}

doi: $10.20964 / 2017.01 .48$

Received: 16 October 2016 / Accepted: 17 November 2016 / Published: 12 December 2016

\begin{abstract}
Nickel thin films were prepared by plating technology on glassy carbon to investigate electrodeposition mechanism and nucleation process. Princeton parstat 2273 station was used to analyze nickel electrodeposition process based on cyclic voltammetry, polarization curves, chronoamperometry and so on. According to the cyclic voltammetry, cathode current and deposition mass of nickel increased extremely when the voltage was more negative than $-1.0 \mathrm{~V}_{\mathrm{SCE}}$. Higher sweeping voltage would lead to stronger cathodic polarization and more deposition mass. Cyclic voltammetry curves with different scan rates indicated that nickel deposition was a kind of irreversible and electrochemistry-limited process. Regarding to typical nucleation model promoted by Scharifker and Hills, the results obtained from chronoamperometry curves with different deposition voltages showed that nickel electrodeposition on glassy carbon was a kind of three dimensional models with progressive nucleation process. Nickel deposition were a kind of grain films with typical bulk structures because three dimensional progressive nucleation mechanism.
\end{abstract}

Keywords: nickel films; electrochemistry mechanism; progressive nucleation;

\section{FULL TEXT}

(C) 2017 The Authors. Published by ESG (www.electrochemsci.org). This article is an open access article distributed under the terms and conditions of the Creative Commons Attribution license (http://creativecommons.org/licenses/by/4.0/). 